\title{
DEVELOPING TOMORROW'S DRUMMING BY STUDYING THE PAST
}

\section{SUMMARY}

Introduction. The master thesis Transmissions of Paradiddles in Jazz and Rock Drumming, A Historical Study (Kayser, 2009) concluded that several paradiddles (specific combinations of single and double strokes) used in military drumming in the $18^{\text {th }}$ and $19^{\text {th }}$ centuries are still in use by today's jazz and rock drummers, though applied in new ways to the drum set.

The Aim of the Study. The purposes of this article is to uncover connections between old military drumming of European-American heritage and drum set playing, and to see if learning from centuries of drumming heritage could also be a way to move ahead and develop the art of drumset playing.

Materials and Methods. In the present article three drum beats, played by three world famous drummers, have been analyzed using the paradiddle and Baton Mesle drum rudiments as analyzing tools.

Results. Gene Krupa used paradiddles derived from military drumming in his basic drumbeat for 'Sing, Sing, Sing'. Steve Gadd used variations of the Single Paradiddle in his drumbeat for 'Late in the Evening'. Drummer Virgil Donati developed the art of drumset playing further by playing two different paradiddle patterns of different lengths simultaneously.

Conclusions. The three drummers of choice for the present article have all used sticking patterns of European-American military drumming heritage as building blocks to create new and original rhythmic patterns on the drumset. Studying older drumming patterns and practices could be one methodical approach to contemporary music pedagogy in the field of drumming, and a way to achieve a sustainable development of the art of drumset playing.

Keywords: music education, musicology, music history, drumming history, drum set, drum rudiment, paradiddle

\section{INTRODUCTION}

By sustainable development I understand a continuous development of an art form, in this case the art of drum set playing. By methodical approaches in contemporary music pedagogy I understand, in relation to the present article, concerns about how one can achieve a sustainable development of an art form.

The master thesis Transmissions of Paradiddles in Jazz and Rock Drumming, An historical Study (Kayser, 2009) was an historical study of the drum rudiments (basic drumming patterns derived from European-American military drumming heritage) called paradiddles. The study concluded that several paradiddles used in military drumming in the $18^{\text {th }}$ and $19^{\text {th }}$ centuries are still in use by today's jazz and rock drummers, though applied in new ways to the drum set.

Further study by the author has shown that paradiddle patterns similar to the Baton Mesle, referred in Mersenne's Harmonie Universelle published 1636 (Sandman, 1977), has recently been used in a completely new way by drummer Virgil Donati (Donati, 2007).

\section{THE AIM OF THE STUDY}

The purpose of my study Transmissions of Paradiddles in Jazz and Rock Drumming, An historical Study (Kayser, 2009) was to learn more about three aspects of drumming: First, I wanted to know how drummers have applied paradiddles to the drumset in jazz and rock genres. Secondly, I wanted to know about teaching practises expressed in drum method books and other 
forms of educational material. Thirdly, drummers' learning processes from within the drum tradition itself.

The purpose of this article is to uncover connections between old military drumming of European-American heritage and drumset playing, and suggest that looking back and learning from centuries of drumming heritage could also be a way to move ahead.

This article will focus on drumming patterns developed by three world famous drumset players on the basis of a European-American military drumming heritage. The point is to uncover how old military drumming patterns were used by these drummers to make entirely new and original drumming performances. And if this could be a methodical approach in music education for sustainable development of the art of drumset playing.

\section{MATERIALS AND METHODS}

The present article is built upon findings in the master thesis Transmissions of Paradiddles in Jazz and Rock Drumming, An historical Study (Kayser, 2009). The study started with the belief that paradiddles could be useful for developing speed and phrasing skills as well as new ways of playing on the drumset. Another idea was that by studying past uses of paradiddles, a repertoire of possible uses could be acquired. From this repertoire a drummer could pick and choose according to the playing situation, and possibly make up new and original uses of the paradiddles.

My sources of information for the thesis were audio and audiovisual recordings of musical performances (LP records, CD records, VHS video, DVD video), drum method books, and drum magazines, educational articles, research publications, and web sites. I also used descriptions and transcriptions of drum performances found in drum books and articles.

In the present article three drum beats will be analyzed using the paradiddle and Baton Mesle drum rudiments as analyzing tools.

\section{RESULTS}

Rope tensioned snare drums were used by military forces in Europe since the fourteenth century. From early seventeenth century snare drums were brought to North America by British and European settlers. Sticking patterns called paradiddles, which were part of military drumming methods both in England and North America from early nineteenth century and onwards, are still in use in drumset playing today in the genres of jazz and rock.

Definition of the term paradiddle:

Paradiddle sticking (assignment of each drum stroke to the left or the right hand) patterns are specific combinations of single and double strokes. The most basic paradiddle, the Single Paradiddle, has the following sticking: left, right, left, left; right, left, right, right. The music notation below is from Charles Stewart Ashworth's drum method published in 1812: A new, useful and complete System of Drum Beating - including the Reveille, the Troop, Retreat, Officers Calls and the whole of the Camp Duty as practiced at Head Quarters, Washington City, intended particularly for the United States Army and Navy:

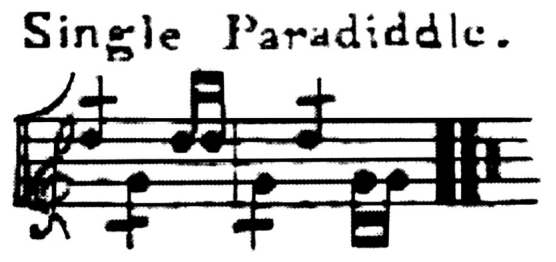

Picture 1. The Single Paradiddle from Ashworth's drum method published in 1812 (Ashworth, 1812, 4)

Left hand was notated with stems up and right hand with stems down. Lines across stems indicate hard strokes. 


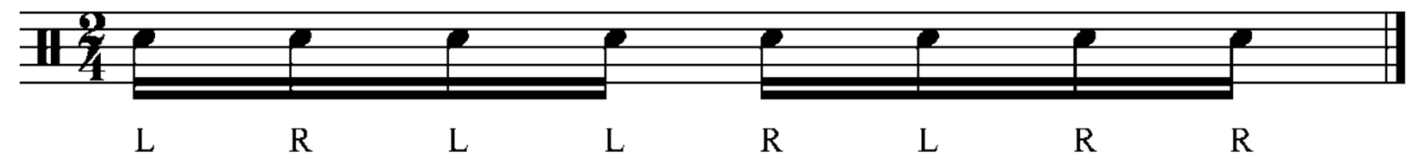

Gene Krupa

The first drumbeat to be transcribed and analyzed here was played by Gene Krupa in the thirties and was recognized as the first drum solo played on a drum set with a jazz orchestra. Krupa became recognized as the drummer who brought the drumset to the forefront of the orchestra as a solo instrument. The following example of music notation is from the drum chart to Sing, Sing, Sing by Louis Prima, published in Gene Krupa Drum Method (Krupa, 1938, 90):

Picture 3. Fragment of drum chart for Sing, Sing, Sing (Krupa, 1938, 90)

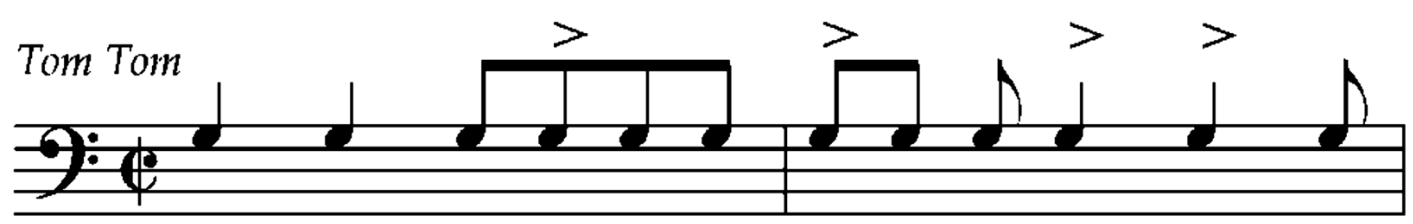

Gene Krupa was the drummer in Benny Goodman's Orchestra in 1935, and the following transcription represents one of Gene Krupa's (Krupa, 1993) interpretations of the above drum chart (Krupa did vary the beat when he played it). I have analyzed the beat in terms of paradiddles. The first measure could alternatively be analyzed as two single strokes followed by another rudiment (basic drumming pattern), the five stroke roll:

Picture 4. One way that Gene Krupa phrased the drumbeat on Sing, Sing, Sing performed with the Benny Goodman Orchestra in 1935 (Krupa, 1993, author's transcription)

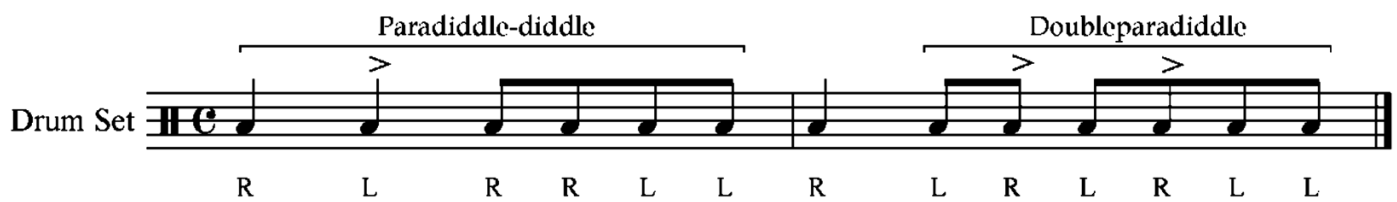

The Paradiddle-Diddle, which Krupa used in the first measure of the drumbeat, was derived from the Flam Paradiddle-Diddle notated in Charles Stewart Ashworth's drum method published in 1812:

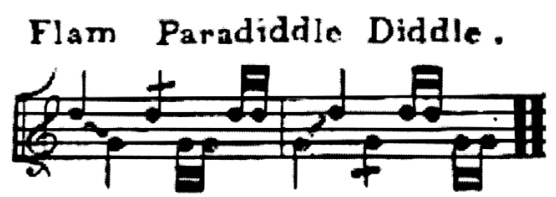

Picture 5. Flam Paradiddle-diddle (Ashworth, 1812, 5)

The sticking pattern was right (preceded by a left hand grace note), left, right, right, left, left; left (preceded by a right hand grace note), right, left, left, right, right.

The Paradiddle-Diddle used by Krupa started with a single stroke instead of a Flam (a single stroke preceded by a grace note). This paradiddle later became a standard drum rudiment and part of Percussive Arts Society International Drum Rudiments: 
19. SINGLE

Paradimdle-dmotx

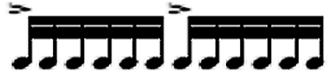

R L R R L L R L R R L L

LRLLRALRLLRA
Picture 6. Rudiment no. 19, called Single Paradiddle-Diddle in Percussive Arts Society International Drum Rudiments (PAS., n. d.)

The Double Paradiddle, which Krupa used in the second measure of the drumbeat, was also notated in Charles Stewart Ashworth's drum method published in 1812:

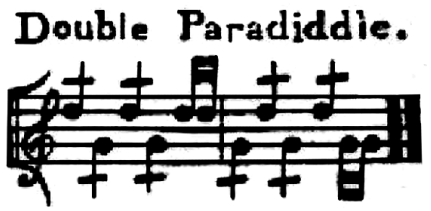

Picture 7. Double Paradiddle (Ashworth, 1812, 4)

Left hand was notated with stems up and right hand with stems down. The Double Paradiddle sticking was: left, right, left, right, left, left; right, left, right, left, right, right.

It should be mentioned here, in order to understand the historical development of drumset playing better, that Gene Krupa studied with a military drummer, Sanford A. Moeller. Moeller had authored The Moeller Book, first published in 1925 (Moeller, 1982), which he built upon a drum method written by George B. Bruce, published in 1862 (Bruce, Emmett, 1865). Then again Bruce built his drum method upon Ashworth's drumming system published in 1812 (Ashworth, 1812) which is referred to in Pictures 1, 5, and 7 above.

Gene Krupa developed the paradiddle further by starting it on different beats of the bar of four/four time. Symbols above the notes indicate arm movements for the particular Downstrokes and Upstrokes taught by Moeller and Krupa. Below are examples from Gene Krupa Drum Method, published in 1938:

(1)

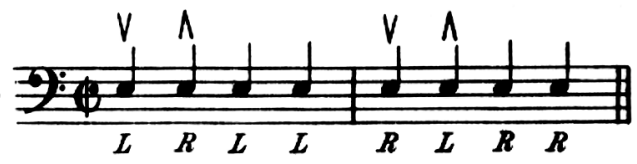

(2)

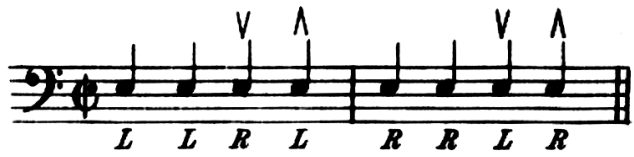

(3)

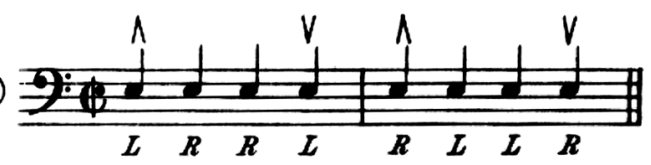

Picture 8. The Single Paradiddle as it appeared in Gene Krupa Drum Method

(Krupa, 1938, 26).

Picture 9. The Single Paradiddle starts with the "diddle" (double stroke)

(Krupa, 1938, 26)

Picture 10. This position of the Single Paradiddle has the "diddle" in the middle (Krupa, 1938, 26)

\section{Steve Gadd}

Below is a transcription of Steve Gadd's basic beat on Late in the Evening performed by Paul Simon (Simon, 2004) on the album One Trick Pony in 1980. I have analyzed the beat in terms of the three paradiddles from Gene Krupa Drum Book (Pictures 8, 9 and 10, above). This is another example of how a drummer has used the paradiddle stickings derived from military drumming to create different rhythms on the drumset in new and original ways; I don't know of any drummer playing this particular beat before Steve Gadd. Right hand played the cymbal or cowbell (notated with x-note heads) and left hand played the tom-toms: 
Picture 11. One of the ways Steve Gadd phrased the drum beat for Late in the Evening (Simon, 2004, author's transcription). The numbers refer to Paradiddle 2 and 3 of the from Gene Krupa Drum Method (Krupa, 1938)

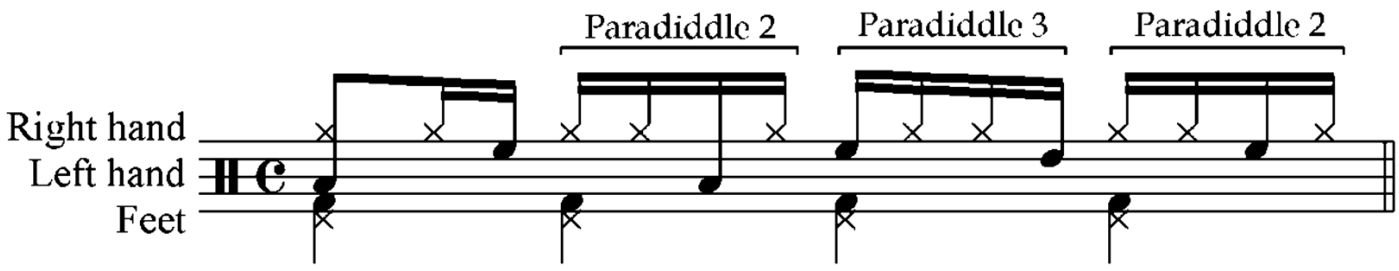

Virgil Donati

In his DVD Live In Stockholm (Donati, 2007), drummer Virgil Donati (who have played with Steve Wai and Planet X) explained what he called 'layers'. Donati developed the use of paradiddles further by playing two paradiddles of different lengths at the same time, and at the same speed, dividing his body into right side and left side. The upper system (played with right side of the body) represents the Single Paradiddle substituting the right foot (RF) for the left hand of the original Single Paradiddle in Ashworth's (Ashworth, 1812) and Krupa's (Krupa, 1938) drum methods (see Pictures 1, 2 and 8), giving the following sticking: RF, right, RF, RF; right, RF, right, right. The lower system (played with left side of the body) represents what Donati called a 'Fiveadiddle' consisting of three single strokes and one double stroke, in this case played between left foot (LF) and left hand giving the following sticking: LF, left, LF, left, left. By combining a five note figure with an eight note figure and using four different sounds, Donati created a complicated polyrhythmic drum beat:

\section{Picture 12. Virgil Donati's “Fiveadiddle” and Single Paradiddle Layer (Donati, 2007)}

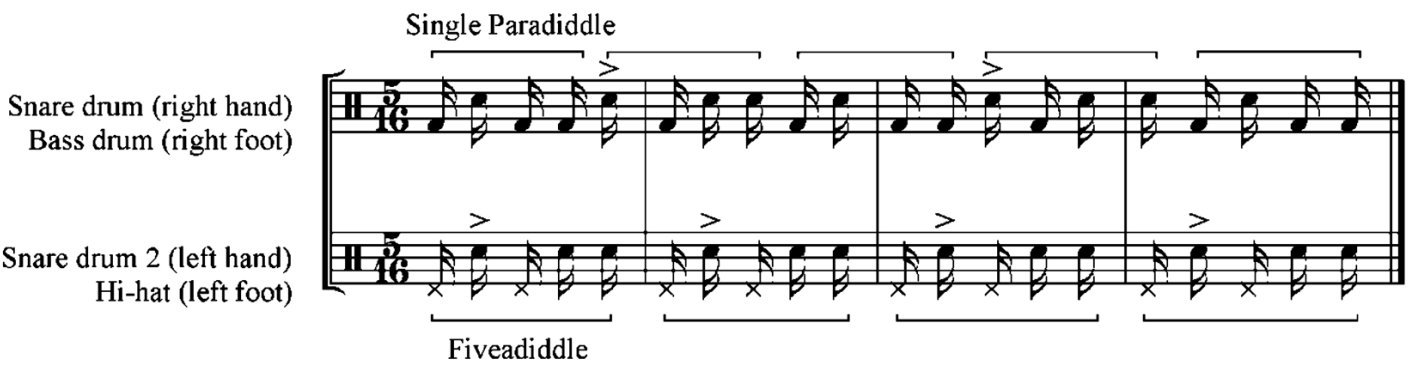

Donati's 'Fiveadiddle' resembles the Baton Mesle in Susan Goertzel Sandman's article Indications of Snare-Drum Technique in Philidor Collection MS 1163 where she refers to Marin Mersenne's Harmonie Universelle published in 1636: '...the beat of the baton mesle [mêle] when each beats sometimes once with each hand and sometimes twice' (Mersenne in Sandman, 1977, 71). 'The baton mesle is related to the paradiddle, an arrangement of single strokes to cause accents to fall alternately to the right and left sticks' (Sandman, 1977, 72). While no music notation for the Baton Mesle was given in Mersenne's text (Mersenne 1957), the example in Sandman's article could be a possible interpretation:

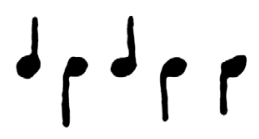

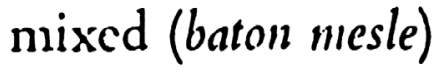

Picture 13. The Baton Mesle in Sandman's article, consisting of three single strokes and one double stroke: left, right, left, right, right

(Sandman, 1977, 72) 
While the author has no evidence that Virgil Donati consciously used a $17^{\text {th }}$ century drumming pattern as reference for his 'Fiveadiddle' and Single Paradiddle layer, Donati's paradiddle pattern is clearly related to the Baton Mesle, however played on snare drum in the $17^{\text {th }}$ century and on drumset in the $21^{\text {st }}$ century. When it comes to the Single Paradiddle however, there can be no question of Donati's awareness of the military and rudimental drumming background of that particular sticking pattern. Donati studied with jazz drummer Philly Joe Jones who in his turn had studied with Charley Wilcoxon, an author of several rudimental drumming (which was derived from military drumming) method books (Donati, 2007).

\section{CONCLUSIONS}

The transcriptions and analyzes above suggest that the three drummers of choice for the present article have all used sticking patterns of European-American military drumming heritage as building blocks to create new and original rhythmic patterns on the drumset. It is interesting that the paradiddle developments on drumset represented in this article by drumbeats of Gene Krupa, Steve Gadd and Virgil Donati were all based on old sticking patterns related to the Baton Mesle explained by Mersenne in 1636.

The present article deals with the group of drum rudiments derived from military drumming called paradiddles. This is only one group of rudiments. There are many others, like rolls, ruffs and flam rudiments. The possibilities for new developments in drumset playing based on the European-American military drumming heritage seem nowhere near exhausted to the author. Therefore, looking back and studying older drumming patterns and practices could be one methodical approach to contemporary music pedagogy in the field of drumming. Creating new patterns and ways of playing drums based on the European-American military drumming heritage could be a way to achieve a sustainable development of the art of drumset playing.

\section{REFERENCES}

1. Ashworth, C. S. (1812) A New, Useful and Complete System of Drum Beating - Including the Reveille, the Troop, Retreat, Officers Calls and the Whole of the Camp Duty as Practiced at Head Quarters, Washington City, Intended Particularly for the United States Army and Navy. http://www.fifedrum.org/resources/music/ashworth/Ashworth_cover.shtml (23.01.2009.)

2. Bruce, G. B., Emmett, D. D. (1865) Drummers' and Fifers' Guide. http://www.fifedrum.org/resources/music/be (23.01.2009.)

3. Donati, V. (2007) Virgil Donati Live in Stockholm [DVD]: Virgildonati.com.

4. Kayser, T. (2009) Transmissions of Paradiddles in Jazz and Rock Drumming. An historical Study. Bergen: Bergen University College, 112 p.

5. Krupa, G. (1938) Gene Krupa Drum Method. New York: Robbins, 95 p.

6. Krupa, G. (1993) Gene Krupa: Jazz Legend [VHS]: DCI Music Video.

7. Mersenne, M. (1957) Harmonie Universelle The Book on Instruments (R. E. Chapman, Trans.). The Hague: Martinus Nijhoff, p. 550-556.

8. Moeller, S. A. (1982) The Moeller Book. The Art of Snare Drumming. Grafton: Ludwig Music Publishing Co, $95 \mathrm{p}$.

9. PAS (n. d.) Percussive Arts Society International Drum Rudiments. http://www.pas.org/Resources/ rudiments/rudiments.html (16.05.2008.)

10. Sandman, S. G. (1977) Indications of Snare-Drum Technique in Philidor Collection MS 1163. The Galpin Society Journal, Vol. 30, May 1977, p. 70-75. http://www.jstor.org/stable/841369 (16.10.2008.)

11. Simon, P. (2004) One Trick Pony [in CD]: Warner.

Master of music education Tormod Kayser

Drum teacher, Bergen University College

Address: Wolffsgate 1, NO-5006 BERGEN, Norway

Phone: +4799255471

E-mail: tormod.kayser@hotmail.com 